\title{
Prácticas letradas en Internet: el caso de Scorchy
}

\author{
(Digital Literacy on the Internet: the Case of Scorchy)
}

\author{
DENISE HERNÁNDEZ Y HERNÁNDEZ 'D , Universidad Veracruzana, Veracruq, México \\ Sofía AMAVizca Montaño (iD), Universidad Estatal de Sonora, Sonora, México \\ Rocío López GONZÁLEz ${ }^{(1)}$, Universidad Veracruzana, Veracruz, México
}

\section{Volumen 2, número 1}

Junio 2017

p. $94-118$

Este número se publicó el 30 de junio de 2017

Artículo recibido: 12 de febrero de 2017

Artículo aprobado: 11 de junio de 2017

ISSN: 2448-5942, doi: https://doi.org/10.36799/el.v2i1.53

\section{Cómo citar:}

Hernández Y Hernández, D., Amavizca Montaño, S., y López González, R. (2017). Prácticas letradas en Internet:

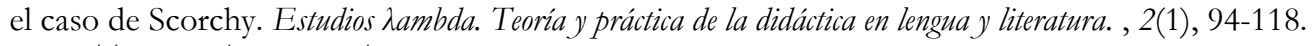
https://doi.org/10.36799/el.v2i1.53

Derechos de autor: El autor o autores conservan en todo momento sus derechos morales y patrimoniales sobre la obra; la obra no se puede alterar, transformar o ampliar; siempre debe reconocerse la autoría del documento referido. Ninguna de las modalidades de los documentos publicados en Estudios Aambda. Teoría y práctica de la didáctica en lengua y literatura tienen fines comerciales de naturaleza alguna.

Los contenidos de este artículo están bajo una licencia de Creative Commons Atribución No Comercial- Sin Derivadas 4.0 Internacional @(1) (3) 


\title{
Prácticas letradas en Internet: el caso de Scorchy ${ }^{1}$ \\ Digital Literacy on the Internet: the Case of Scorchy
}

\author{
DENISE HERNÁNDEZ Y HERNÁNDEZ ${ }^{2}$ \\ Sofía AMAVIZCA Montaño ${ }^{3}$ \\ Rocío LÓPEZ GONZÁLEZ
}

\section{RESUMEN}

La emigración hacia prácticas comunicativas digitales ha sido vertiginosa por lo menos en las últimas dos décadas, sobre todo para una generación que tuvo que aprender a usar las Tecnologías de Información y Comunicación (TIC) de manera casi autodidacta. Presentamos una investigación cuyo objetivo es describir y analizar el impacto que han tenido las TIC en las prácticas letradas de un grupo de adultos profesionales que viven en el extranjero, nos centramos en un estudio de caso en donde la metodología empleada son entrevistas en profundidad con la triangulación de documentos capturados de la red, examinados desde la perspectiva de los Nuevos Estudios de Literacidad. Analizamos la producción de textos a través del uso de un blog llamado El viaje de Scorchy, en donde se valora la apropiación de nuevas formas de uso de la lectura y la escritura. Se analizan 64 textos publicados a lo largo de tres años y siete meses. Se observó cómo el informante se familiarizó con estas formas de comunicación, así como la resistencia, la obstinación, la nostalgia por abandonar o modificar el uso de las prácticas letradas tradicionales y comenzar a adaptarse a una sociedad cada vez más digitalizada.

PALABRAS CLAVE: prácticas letradas, literacidad, TIC, blog.

\begin{abstract}
The migration towards digital communicative practices has been intense, at least for the last two decades, especially for a whole generation whose members had to learn, practically through self-study, how to use the Information and Communication Technologies (ICT). The main aim of this research paper is to discover and analyze the impact of ICT use in the literacy practices of a group of adult professionals living abroad. With the New Literacy Studies approach, we used the case study research method which included in-depth interviews along with data triangulation from websites. A blog named El viaje de Scorchy (Scorchy's Travels) was used to analyze text production where we valued new ways for reading and writing use. 64 blog posts published over a three-year seven-month period were analyzed. It was evident for us the way the informant got used to these modes of communication, as well as the reluctance, stubbornness or nostalgia to give up or modify these traditional literacy practices and how they started to adapt to a more digital society.
\end{abstract}

KEY WORDS: Literacy practices, literacy, ICT, blog.

\footnotetext{
${ }^{1}$ Este artículo es producto de la Red Temática Literacidad Digital en la Universidad (RED-LDU), reconocida y aprobada por CONACyT desde mayo del 2016, conformado por investigadores, académicos y estudiantes de diversas instituciones de educación superior nacionales y del extranjero.

${ }^{2}$ Doctora en Comunicación Lingüística y Mediación Multilingüe por la Universidad Pompeu Fabra, Barcelona, España. Técnico Académico del Programa de Investigación e Innovación en Educación Superior de la Universidad Veracruzana, México. Miembro de la Red Temática Literacidad Digital en la Universidad. Candidato a Investigador Nacional SNI. nadhernandez@uv.mx

${ }^{3}$ Lic. en Literaturas Hispánicas, Mtra. en Educación por la Universidad del Valle de México, Dra. en Humanidades por la Universidad de Sonora. Profesora investigadora de tiempo completo en la Universidad Estatal de Sonora, Hermosillo, México. Miembro de la Red Temática Literacidad Digital en la Universidad. amavizcasofia@yahoo.com.mx

${ }^{4}$ Doctora en Pedagogía por la Universidad Nacional Autónoma de México. Investigadora del Programa de Investigación e Innovación en Educación Superior de la Universidad Veracruzana. Miembro de la Red Temática Literacidad Digital en la Universidad. Es Nivel 1 en el Sistema Nacional de Investigadores de México. Correo: rociolopez@uv.mx
}

Artículo recibido: 12 de febrero de 2017

Artículo enviado a corrección: 14 de marzo de 2017

Aprobado: 11 de junio de 2017

Hernández, Amavižca y González doi: https://doi.org/10.36799/el.v2i1.53 Volumen 2, número 1, Año 2017, ISSN: $2448-5942$ 


\section{INTRODUCCIÓN}

Las Tecnologías de Información y Comunicación (TIC) han sido un elemento primordial para los cambios en las prácticas y formas de organización social (Brown, 2000). Las hemos incorporado de tal manera en nuestra vida que se han vuelto invisibles. Esta incorporación no sucedió de un día para otro -aunque las nuevas generaciones no lo conciban así- ha sido un cambio gradual, lento, doloroso, nostálgico para algunos y sorprendente e inimaginable para otros, sobre todo para aquellos que tuvimos que adaptarnos -o no- a una vida cada vez más digitalizada (Hernández, 2017).

Por lo anterior nos dimos a la tarea de conocer, analizar y documentar la actividad en espacios digitales de jóvenes adultos que les tocó enfrentarse a la tecnología. En este trabajo presentamos, de manera general, las prácticas letradas que realiza nuestro grupo de informantes en la pantalla y profundizamos en el análisis de uno de estos informantes ya que tiene una producción escrita - muy interesante- en su blog El viaje de Scorchy.

Este grupo de personas son usuarios de una tecnología a la que tuvieron que adecuarse y probablemente esta adaptación ha repercutido en la forma en que llevan a cabo sus prácticas letradas en el mundo digital. Además, estas formas de apropiación de la tecnología, varían en comparación con los más jóvenes. No estamos afirmando que su comportamiento en el mundo virtual esté determinado por haber nacido antes o después de la revolución tecnológica, pero sí creemos que tiene implicaciones y consecuencias (Hernández, Ramírez-Martinell \& Cassany, 2014).

\section{Los Nuevos Estudios de Literacidad}

Nuestra investigación se inserta dentro de los Nuevos Estudios de Literacidad (NEL; New Literacy Studies, en inglés) con el objetivo de describir y analizar el impacto que las TIC han tenido en las prácticas letradas de un grupo de adultos mexicanos que estudian o trabajan en el extranjero. En los NEL se toma en cuenta el ámbito social, cultural y el momento histórico donde se desarrolla la actividad comunicativa; es decir, la lectura y la escritura se conciben como prácticas situadas para alcanzar objetivos específicos (Gee 2000; Camitta, 1993; Barton \& Hamilton 2004; Cassany \& Hernández, 2012), por lo que deben ser estudiadas dentro de este contexto para construir un retrato verosímil de ellas (Lankshear, Gee, Knobel \& Searle, 1997).

Hernández̧, Amaviz̧ca y González, doi: https://doi.org/10.36799/el.v2i1.53 Volumen 2, número 1, Año 2017, ISSN: $2448-5942$ 
Dentro del desarrollo de los NEL se distinguen dos momentos. El primero tiene sus antecedentes en la década de los 80 , con los primeros trabajos que trataban de describir los fundamentos sociales de la lectura y la escritura. La investigación más conocida es la de Scribner \& Cole (1981) con la comunidad Vai de Liberia; pero también queremos destacar el trabajo etnográfico que realiza Heath (1983) en Ways with words, en este trabajo la autora realiza una comparación entre dos comunidades de Carolina del norte en EEUU, sobre los usos de la lengua escrita de la clase trabajadora de personas blancas con las de personas negras. Si bien tienen experiencias distintas con la lengua escrita, ambas culturas comparten ciertas prácticas de lectura y de escritura que, irónicamente, son rechazadas por la escuela por no considerarlas como formativas para la educación de los niños. La idea de estos estudios era explorar la literacidad más allá del entorno escolar y documentar la lectura y la escritura habitual ordinaria; es decir, qué cosa leen y escriben las personas en su vida normal, privada y sobre todo cómo lo hacen.

En un segundo momento hubo un grupo de investigaciones, en la década de los 90, con una orientación más teórica. Tenían la idea de construir una teoría de la literacidad como práctica social (Street, 1984, 1993, 1995; Gee 1990, 2000; Barton \& Hamilton 2004). Discuten conceptos básicos y proponen construir una terminología común. Dentro de esta orientación la propuesta más completa y apreciada es la de Barton \& Hamilton (2004), quienes analizan seis principios sobre la naturaleza de la literacidad desde la teoría social:

1. La literacidad es entendida como un conjunto de prácticas sociales, que se pueden inferir de los eventos mediados por los textos escritos.

2. Hay diferentes literacidades asociadas con diferentes dominios de la vida.

3. Las prácticas letradas son reguladas por instituciones sociales y por relaciones de poder, algunas se vuelven más dominantes, visibles e influyentes que otras.

4. Las prácticas de literacidad cumplen objetivos y están insertas en prácticas sociales y culturales más amplias.

5. La literacidad está socialmente situada.

6. Las prácticas de literacidad cambian y algunas otras son adquiridas a través de procesos informales de aprendizaje y de construcción de sentido.

Hernández̧, Amaviz̧ca y González, doi: https://doi.org/10.36799/el.v2i1.53 Volumen 2, número 1, Año 2017, ISSN: $2448-5942$ 
Los NEL articulan la concepción de literacidad como práctica social (Street, 1995) con tres conceptos teóricos básicos: las prácticas, los acontecimientos y los dominios letrados.

\section{Práctica letrada}

Las prácticas letradas están socialmente organizadas y reguladas, son aprendidas dentro de distintos escenarios, son las formas culturales generales en que la gente utiliza los textos en situaciones socioculturales específicas (Kalman, 2003), y se ven involucrados los valores, actitudes y sentimientos de las personas.

Este concepto nos remite al estudio The Psychology of Litercy (1981) de Sylvia Scribner y Michael Cole que es uno de los trabajos más conocidos acerca de los usos sociales de la lengua escrita. Estos autores indagaron acerca de los usos de la lectura y la escritura entre los Vai, un pueblo de África Occidental en Liberia, trilingüe y tri-letrado. En esta cultura coexisten tres lenguas -el vai, el inglés y el árabe-cada una con su representación escrita propia y asociada a diferentes esferas de actividad: el Vai, una escritura basada en un sistema silábico de representación utilizada para la expresión personal y para la conducción de negocios familiares y de la comunidad; la escritura del idioma inglés para tratar asuntos con el gobierno, con las escuelas y con instituciones económicas; y la escritura arábiga, destinada a fines religiosos. Su investigación sugiere que las prácticas letradas están socialmente organizadas y reguladas y son aprendidas dentro de distintos escenarios.

Para Barton \& Hamilton (1998) las prácticas letradas son las formas culturales generales en que la gente utiliza los textos en situaciones socioculturales específicas; es decir, es lo que la gente hace con la lectura y escritura. No podemos reducirlas a unidades simples de comportamiento porque también se ven involucradas las distintas formas de pensamiento de las personas, sus valores, actitudes, sentimientos, así como el posicionamiento hacia las formas de lectura y escritura asociados a diversos aspectos sociales (Street, 1993). No son, por lo tanto, conductas observables, son formas abstractas culturalmente reguladas. Esto determina la forma en que se lee y se escribe, asimismo los usos y valores que se le atribuyen a los textos están socialmente legitimados dentro de cada contexto. Esto sugiere, entonces, que a través de patrones sociales las prácticas letradas se socializan, regulando así la producción, el acceso, el uso y la distribución de textos.

Hernández̧, Amaviz̧ca y González, doi: https://doi.org/10.36799/el.v2i1.53 Volumen 2, número 1, Año 2017, ISSN: $2448-5942$ 
Bajo esta perspectiva es interesante también el papel que juegan las instituciones -como la escuela, la familia, el gobierno, la iglesia-, porque a través de ellas se regulan también las prácticas letradas cotidianas.

Para los NEL el concepto de práctica letrada es importante porque a través de él se puede explorar, documentar y analizar lo que hacen las personas con los textos, cómo los utilizan y con quién los comparten. Para poder documentar esto, los NEL recurren al estudio de los acontecimientos letrados, que trataremos a continuación.

\section{Acontecimiento letrado}

Los acontecimientos letrados se encuentran envueltos en situaciones de interacción de los sujetos con el texto escrito. El hecho de que sean observables significa que son visibles y que, por lo tanto, puede aislarse y fotografiarse, por ejemplo. Para analizarlos hay que describir las reglas subyacentes a estos, el material escrito y los modos de relación con ese material. Dentro de los NEL las prácticas y los acontecimientos letrados se complementan. El acontecimiento permite observar a nivel micro una práctica letrada, además está sometido y definido a prácticas generales de lectura y escritura (Barton \& Hamilton, 1998), que a su vez están asociadas a escenarios concretos: familia, escuela, religión, ocio, hogar, TIC, comunidad, trabajo. Cada escenario se encuentra regulado por normas, prácticas, ritos y relaciones de comportamiento que dan estructura a las interacciones sociales. En resumen, el concepto de escenario letrado ayuda a comprender lo que hacen las personas con la lectura y la escritura.

Dentro de los NEL las prácticas y los acontecimientos letrados están vinculados y se complementan. El acontecimiento permite observar el nivel micro de una práctica letrada, además están sometidos y definidos a prácticas generales de lectura y escritura (Barton \& Hamilton, 1998), que a su vez están asociadas a dominios o escenarios concretos del mundo social.

\section{Dominios letrados}

La representación de dominios letrados, dentro de los NEL, es una clasificación abstracta que permite ordenar los diversos tipos de textos y prácticas, además nos ayuda a entender mejor lo que la gente lee y escribe en los distintos escenarios sociales. Barton \& Hamilton nos ofrecen una definición de este término:

Hernández, Amaviz̧ca y González, doi: https://doi.org/10.36799/el.v2i1.53 Volumen 2, número 1, Año 2017, ISSN: $2448-5942$ 
"Domains are structured, patterned contexts within which literacy is used and learned. Activities within these domains are not accidental or randomly varying: there are particular configurations of literacy practices and there are regular ways in which people act in many literacy events in particular context. Various institutions support and structure activities in particular domains of life. These include family, religion and education, which are all social institutions” (Barton \& Hamilton 1998, p. 10).

Los dominios más estudiados dentro de los NEL son: familia, escuela, religión, ocio, hogar, TIC, comunidad, trabajo. Cada uno de ellos está definido y regulado por normas, prácticas, ritos y relaciones de comportamiento que dan estructura a las interacciones sociales. Las prácticas letradas que se asocian a cada dominio reciben un nombre en particular, por ejemplo, las prácticas de lectura y escritura en la escuela se denominan literacidades académicas, las asociadas con las TIC se llaman literacidades digitales.

Por otra parte, Gallego \& Hollingsworth (2000, p. 5) hablan de múltiples literacidades y las clasifican de la siguiente manera:

"School literacies- the learning of interpretive and communicative processes needed to adapt socially to school and other dominant language contexts, and the use or practice of those processes in order to gain a conceptual understanding of school subjects

Community literacies- the appreciation, understanding, and / or use of interpretive and communicative traditions of culture and community, which sometimes stand as critiques of school literacies

Personal literacies- the critical awareness of ways of knowing and believing about self that comes from thoughful examination of historical or experiential and gender-specific backgrounds in school and community language settings, which sometimes stands as critique of both school literacies and community literacies".

Estas investigadoras argumentan que esta división de literacidades que elaboraron a partir de su experiencia no es estática, ni mucho menos jerárquica, las categorías tienen puntos en común y en ocasiones se hace difícil determinar dónde acaba una y comienza otra.

En síntesis, el concepto de dominio letrado nos ayuda a comprender lo que hacen las personas en varios escenarios con la lectura y escritura. Sin embargo, el objetivo no es buscar Hernández, Amaviz̨ca y González, doi: https://doi.org/10.36799/el.v2i1.53 Volumen 2, número 1, Año 2017, ISSN: $2448-5942$ 
una coincidencia completa con el entorno físico al cual se asocia, sino llevarse a cabo en un dominio o en otro.

\section{METODOLOGÍA}

\section{Selección de los informantes}

El grupo de informantes está constituido por 10 personas de edades entre los 24 y 38 años. Todos son mexicanos (siete varones y tres mujeres), ocho de ellos se encontraban en el extranjero por estudios posgrado y los otros dos laboran profesionalmente. Después de contactarlos por correo electrónico o de manera personal, se acordó una primera cita con ellos para explicarles el propósito de la investigación y cómo procederíamos a realizar las entrevistas.

La localización de la mayoría de los informantes se llevó a cabo a través del grupo en Google llamado "Becarios CONACyT en España" (cuya dirección es: https://groups.google. $\mathrm{com} /$ forum/\#!forum/becariosCONACyT), al ser un grupo cautivo decidimos ponernos en contacto con el creador del mismo y pedir permiso para colgar un aviso en donde se les invitaba a participar en una investigación, se les explicaba que necesitábamos de su colaboración para realizar una serie de entrevistas; el creador del grupo fue el primero en responder a nuestro mensaje y en aceptar participar con nosotros. El resto de los informantes fueron contactados a través de amigos y conocidos.

\section{Consideraciones éticas}

Desde el primer encuentro que se tuvo con cada informante se les explicó que las entrevistas serían grabadas en audio y que se conservaría su anonimato. Nosotros decidimos el seudónimo dado a cada uno de ellos, pero se conservó el nombre original de amigos y familiares. Al ser miembros - la mayoría- de una comunidad dedicada a la investigación, tenían cierto conocimiento del procedimiento llevado a cabo en este tipo de proyectos, debido a ello ninguno manifestó tener algún inconveniente con el trato que pudiéramos darle a sus datos (básicamente capturas de pantalla y fotografías).

Como parte del acercamiento para ganar su confianza -y para agradecer el tiempo que nos dedicaban-, aceptamos un par de invitaciones para asistir a reuniones, paseos, comidas, etc. 
Así nos enterábamos de las cosas acontecidas en su vida cotidiana y personal, si alguna de esa información nos parecía relevante para este trabajo tomábamos nota de ello y, en una entrevista posterior, retomábamos el tema para que fueran ellos mismos quienes nos lo describieran.

\section{Entrevistas}

Se hicieron 27 entrevistas semiestructuradas, con una duración aproximada de una hora a lo largo de cuatro años. La mayor parte de ellas se llevaron a cabo en el domicilio de los informantes, otras se realizaron en la universidad donde ellos estudiaban; una se hizo en una cafetería y dos más por Skype. El tener acceso a sus hogares o a los sitios donde estudiaban, nos permitió conocer su entorno, averiguar con qué tipo de materiales de lectura contaban o cómo estaba distribuido y conformado su lugar de trabajo, con qué equipo tecnológico trabajaban y dónde estaba localizado.

Como parte de la investigación se les informó que era necesario tener acceso a las diferentes redes sociales o sitios web en los cuales participaban, no tuvimos problema en acceder a ellos.

Se elaboró un guion general para todos los informantes que se utilizó en la primera entrevista; los guiones posteriores fueron más personalizados, se elaboraron de acuerdo a las dudas surgidas de las entrevistas previas y generamos nuevas preguntas sobre la actividad que tenían en Internet.

De manera general los guiones de entrevista se centraron en los siguientes temas:

- En la primera entrevista se recolectó información general sobre sus prácticas electrónicas de comunicación, los géneros electrónicos que utilizaban, las páginas de ocio consultadas, si contaban con redes sociales o blogs personales. Otros temas rescatados (pero que no se discuten en este trabajo) fueron el primer contacto que tuvieron con la computadora, si recibieron instrucción formal o aprendieron por su cuenta; se indagó sobre las cuentas de correo electrónico, cuándo abrieron su primer cuenta, quién les ayudó a hacerlo, cómo se enteraron de lo que era una cuenta de correo, cuántas tienen en la actualidad y si las utilizan para diferentes propósitos (para profundizar en estos temas consultar Hernández. D., 2016).

Hernández̧, Amaviz̧ca y González, doi: https://doi.org/10.36799/el.v2i1.53 Volumen 2, número 1, Año 2017, ISSN: $2448-5942$ 
- En la segunda entrevista se profundizó en el uso diferenciado de los formatos electrónicos versus los formatos impresos, en la división del tiempo de trabajo y las actividades de ocio frente a la computadora. También se indagó en las implicaciones que tenía hacia su vida relacionarse socialmente frente a la pantalla y cómo vivían ellos este cambio. Frente a las posibilidades del medio electrónico nos interesaba saber qué prácticas en papel habían dejado de realizar y por qué; preguntamos si eran capaces de realizar varias actividades a la vez frente al ordenador y cuáles eran estas actividades. En esta segunda entrevista también se investigaron los siguientes temas (que para efectos de este artículo no se presentan los resultados), averiguamos si hacían una distinción entre el tiempo que pasaban en la computadora realizando cuestiones de trabajo o escolares y el tiempo que destinaban a actividades de ocio; preguntamos qué criterios empleaban para hacer esta diferencia y cuál era el tiempo que destinaban a cada actividad; como miembros de una comunidad extranjera se ahondó sobre las ventajas de los mensajeros instantáneos para comunicarse con sus amigos y familiares, cuáles utilizaban y si hacían distinciones entre ellos y por qué.

- La tercera entrevista resultó ser más personalizada debido a que llevábamos tiempo indagando en sus redes sociales o sitios web, contamos con material sobre las páginas que frecuentaban (sobre noticias, para bajar música, ver películas, escuchar la radio, páginas deportivas), sobre los blogs que han creado o en los que participan y debido a que teníamos acceso a sus páginas de Facebook, hi5, Picasa, Messenger, Skype y Twitter también contamos con material de estas redes y mensajeros. Durante la entrevista intentamos averiguar cómo se manejan dentro de sus redes sociales, quiénes eran sus contactos, qué tipo de material subían, cada cuanto actualizaban sus datos, cuándo los consultaban. Lo que se trató de manera generalizada fueron las preguntas en torno a su escritura: cómo escriben ellos en el formato electrónico, si escriben de una forma convencional o emplean la escritura ideofonemática, hacen alguna diferencia dependiendo del destinatario, cómo les afecta este tipo de escritura.

- Conforme seguimos su actividad virtual nos surgieron más preguntas y solicitamos realizar una cuarta entrevista en algunos casos. Para este momento algunos ya habían regresado a México, otros cambiaron de trabajo o se mudaron de país y algunos más se 
casaron y tuvieron hijos. En la mayoría de los casos pudimos dar seguimiento a lo que acontecía en sus vidas personales a través de lo que publicaban en sus redes sociales y notamos ciertos cambios que llamaron nuestra atención. No ocurrió así en dos casos, ya que los informantes en cuestión no eran muy propensos a la tecnología y preferían mantener comunicación con sus allegados utilizando otros medios como las llamadas telefónicas o bien acordando encuentros de manera personal.

\section{Transcripción y procesamiento de las entrevistas}

El interés de las entrevistas se centra en el contenido, es por eso que en las transcripciones (ver la Tabla 1) sólo se marcan algunos rasgos suprasegmentales; pese a que el discurso oral tenga otro tipo de sintaxis están escritas en español estándar con normativa escrita. El programa utilizado para procesar y analizar las transcripciones fue $A T L A S$-ti.

Tabla 1. Código de transcripción

\begin{tabular}{|c|l|}
\hline SÍMBOLO & \multicolumn{1}{|c|}{ DESCRIPCIÓN DEL SIGNIFICADO CODIFICADO } \\
\hline$[\mathrm{xxx}]$ & Discurso del entrevistador \\
\hline$\ldots-$ & Palabra incompleta \\
\hline$:$ & Alargamiento de palabra \\
\hline$\ldots$ & Pausa larga \\
\hline, & Pausa corta \\
\hline XXX & Discurso incomprensible \\
\hline MAÝ́SCULA $]$ & Indicaciones de lo que pasaba en la entrevista o aclaración de algún hecho \\
\hline Cursiva & Cambio de idioma \\
\hline /xxx $/$ & Transcripción fonética \\
\hline$\underline{\mathrm{xxx}}$ & Discurso de una tercera persona \\
\hline
\end{tabular}

Fuente: Elaboración propia

A continuación ofrecemos una caracterización general del tipo de transcripción aplicada: 
- Hemos transcrito las interacciones tanto del discurso de los informantes, como los de la entrevistadora y - un par de ocasiones- de una tercera persona.

- La transcripción sigue las normas ortográficas convencionales, pero no se utilizan todos los símbolos de puntuación tradicionales, se limita a respetar las pausas y alargamientos producidos por los informantes.

- No se corrigieron las construcciones gramaticales incorrectas desde punto de vista de la normativa, con la idea de mantener el carácter genuino de las reflexiones.

- Se consideraron algunos aspectos proxémicos relevantes para contextualizar la transcripción.

- No se consideraron aspectos paraverbales.

\section{Imágenes y fotografías}

Como parte del análisis realizamos capturas de imágenes de sus sitios web personales o profesionales, de las fotografías, archivamos los textos que escribieron, así como los comentarios recibidos por los visitantes de sus páginas.

$\mathrm{Al}$ formar parte de su comunidad de amigos en las redes sociales podíamos estar al tanto de lo que publicaban al momento de conectarnos a nuestra propia red social. Cuando veíamos alguna actividad interesante por su parte realizábamos la captura de imagen para archivarla. En algunas ocasiones las entrevistas y las capturas se realizaron durante el mismo periodo, esto nos daba la oportunidad de incluir en los guiones de entrevista preguntas específicas de alguna actividad o publicación en particular.

No siempre contábamos con una cuenta de una determinada red social que los informantes usaran, así que abrimos las que fueran necesarias. Conforme íbamos siguiendo su actividad a través de sus publicaciones nos percatamos también que tenían cuentas en otras redes o blogs que no nos habían mencionado en las entrevistas; en algunos casos no fue posible hacerlo ya que las aplicaciones que empleaban sólo funcionaban con determinados dispositivos electrónicos con los cuales nosotros no contábamos.

Hernández̧, Amaviz̧ca y González, doi: https://doi.org/10.36799/el.v2i1.53 Volumen 2, número 1, Año 2017, ISSN: $2448-5942$ 
Con respecto a los sitios web, en ocasiones eran ellos quienes nos comentaban que participaban en otros espacios virtuales, entonces les pedíamos la dirección electrónica o su nombre de usuario para localizarlos. Para los informantes que contaban con un blog personal, además de capturar algunas imágenes, archivamos en un procesador de textos aquello que escribieron, así como los comentarios recibidos por los visitantes de los blogs.

\section{Categorías de análisis}

La primera clasificación de categorías se realizó a través de un esquema general e inicial basado en los temas que habíamos elaborado en los guiones de entrevista. Al realizar las transcripciones fuimos elaborando nuevas categorías que incluíamos en el programa de $A T L A S$ ti., lo cual nos llevaba a modificar toda nuestra categorización. Estas primeras pruebas de análisis las realizamos con un sólo informante, lo elegimos porque era del que teníamos más datos y considerábamos que eran los más ricos para analizar; de esta forma creímos que podríamos generalizar o elaborar categorías y subcategorías para el resto de los informantes. Cuando quedábamos satisfechos con el análisis añadíamos más transcripciones al programa, lo que nos llevaba nuevamente a modificar las categorías y subcategorías ya elaboradas.

Es así que para el análisis total de los datos elaboramos 15 categorías y 49 subcategorías, para este trabajo nos centraremos sólo en dos categorías que describimos a continuación con sus respectivas subcategorías:

1. Actividad en la computadora: Se refiere al tipo de actividades y búsquedas de ocio que realizan en pantalla -con o sin conexión a Internet- en los ámbitos privados, de ocio, recreación, doméstico, social y familiar.

a) Actividades diarias, rutinarias: Se refiere a las actividades que realizan en el ordenador de manera cotidiana, algunos informantes nos describieron de manera específica cómo organizaban estas actividades pero también se tomó en cuenta lo que acostumbran a hacer de manera regular.

b) Actividad y búsquedas ocio: Son las actividades de ocio que acostumbran a realizar en el ordenador: búsquedas de información general o cuestiones de interés, páginas donde acostumbran ver películas o series de televisión, escuchar música, revisar sus redes sociales, comprar cosas, jugar, chatear.

Hernández̧, Amaviz̧ca y González, doi: https://doi.org/10.36799/el.v2i1.53 Volumen 2, número 1, Año 2017, ISSN: $2448-5942$ 
c) Organización de consultas a cuentas y documentos: Se refiere a los gestionadores que emplean para revisar sus cuentas de correo electrónico o redes sociales. También comprende programas o criterios para clasificar y respaldar su información personal y/o escolar-laboral en el ordenador.

d) Multitarea: Cuántas y qué actividades son capaces de realizar al mismo tiempo frente al ordenador.

e) Manejo ordenador: Qué tan capaces se sienten con el manejo del ordenador, si utilizan comandos o el mouse; cómo organizan y clasifican las páginas que consultan con mayor frecuencia.

2. Páginas personales: Son las páginas o blogs creados por los informantes (personales o académicos).

a) Scorchy: Blog personal de uno de los informantes: cómo surgió la idea del blog, tipo de textos que cuelga, comentarios que recibe.

b) Noé blog: Blog personal de uno de los informantes.

c) Otros blogs: Son blogs o páginas personales que abrieron pero no consultaron más, blogs poco relevantes para ellos mismos, blogs que consultan con menor frecuencia o que consultan por alguna situación específica.

\section{RESULTADOS}

\section{Panorama general de las prácticas digitales}

A pesar de que la computadora es básicamente una herramienta de trabajo para la mayoría de los informantes, dedican varios momentos del día a realizar actividades de ocio en la pantalla, se pasan el día leyendo y escribiendo, alternando géneros muy diferentes, saltando de lo profesional y académico (escribir su tesis, buscar información, elaborar ponencias y artículos) a lo personal y lúdico (ver películas, escuchar música, chatear con sus amigos o familia).

hay una división, claro, entre, estoy trabajando y dejo de, de trabajar [ajá] pero estructurado no, o sea, nunca planeo o, voy a hacer esto a esta hora, o: voy a darme una hora para leer el correo, de repente llega un correo y digo ah, lo leo, y dejo de trabajar 
un rato, o sea [ah ya] muy poca planeación es una de mis grandes [m:] desventajas soy muy disperso, me voy por las ramas siempre, o sea en todo $[\mathrm{A} 2 / \mathrm{OM} / 2 / 11]$

Emplean los blogs y redes sociales para conservar y compartir lo que escriben y publican. Además, en Internet han encontrado espacios para dar a conocer sus estudios profesionales y compartirlos con sus colegas, han recurrido a las páginas web personales, donde sabiamente han explotado sus conocimientos sobre los idiomas, escribiendo su información en distintas lenguas, logrando así llegar a una audiencia más amplia.

luego la ventaja de Google Reader es que, también te permite algo como Facebook, tener contactos que leen también noticias como tú, hay muy poca gente ahorita sólo mi ex jefe en donde trabajaba en México, que es un crack en informática, entonces bueno ahí está y cada vez que el comparte comparte: cinco cositas igual que yo y leo las cosas que él comparte [mju] o sea porque sé que ya las depuró digamos, él ya fue un filtro de la basura, él lee otros, otros, otras páginas que yo no leo, yo leo unas cuantas que él no lee entonces vamos compartiendo digamos [ah] esto es interesante, esto es interesante y ahí lo vamos leyendo XXX y puedes dejar comentarios 'oye y por qué dijeron eso', y ya te responden ‘oye, tal vez fue por eso' [ah:] cositas [ah está bien] si, bueno, es más tecnológico es demasiado tecnológico [A2/OM/2/14]

El valor que le dan a la escritura convencional es importante, a pesar de que el medio electrónico permite cierta flexibilidad al momento de escribir, son cuidadosos con los textos que publican.

detesto un poquito eso, de que, detesto un poquito la [las] la pereza que tiene la gente [aja] de, de poder escribir real ¿no? el que utilizan, que qué pasa, que, que te pongan una, una / ka/ [mju] lo que me, me, me, me demuestra la pereza que tiene la gente de escribirte algo así, eh: lo he hecho, sinceramente, a lo mejor en un mensaje, m: de: móvil a móvil, lo he hecho [mju] muy pocas veces te puedo asegurar, muy pocas veces, muy puntual, casi nunca lo hago, más bien nunca lo hago te puedo decir, eh: detesto, si detesto esto ¿no? creo que, también puede ser un, una parte de ejercicio de poder escribir y poder rectificar que algunos acentos, por ejemplo, algunas faltas gramaticales entonces, entonces creo que es un ejercicio entonces hay que seguirlo haciendo [A2/JO/3/35] 
Muchas de las prácticas letradas que realizaban en formatos impresos han migrado a los espacios digitales: lectura de artículos de investigación, envío de cartas, mandar postales, en ocasiones por una cuestión económica.

no compro eh libros porque aquí hay muy buenas bibliotecas, y no compro pe...periódicos porque hay muy buenas bibliotecas [risas] sí, pero sí lo compraría, estuve tentado hace un mes eh en: suscribirme eh en enero, hace un mes no, en enero estuve tentado a, suscribirme a El País ¿no? [m:] porque sí me encanta el que llegue el periódico a tu casa [mju]; es un placer lo que me ge...- me parece, todos los días te levantas y dices 'wow que esté el periódico en mi casa' [el periódico] ¿no? y claro leerlo con un cafecito [si] eso me encanta, claro lo que pasa es que, son trescientos euros [mju] o sea es una decisión que hay que tomar, con el piso para que todos, le caigan ¿no? [claro] sí, sí, digo en México es mucho más barato [si] y como becario de CONACyT [risas] hacer esa compra como que no, no $[\mathrm{A} 2 / \mathrm{PA} / 2 / 11]$

Pero otras prácticas siguen conservando su origen en papel: diarios personales, agenda telefónica, lectura recreativa, corrección de trabajos académicos. Además el papel sigue teniendo mucha presencia en sus vidas aun cuando en este momento tengan inconvenientes para acceder a él debido al costo que les supone (siendo estudiantes en un país extranjero). En todo caso recurren a las bibliotecas para leer la prensa o consultar libros, tanto académicos como recreativos.

tengo un diario [un diario] donde, no todos los días, también va por temporadas, pero: intento escribir lo primero que se me viene a las mañanas, eh, lo escribo ¿no? y cuando:, por ejemplo:, viajo o: este fin de semana que no me llevé el ordenador y que estuve viajando entonces me llevé un libro, entonces en el libro iba apuntando: subrayando cosas y luego en el cuaderno iba, haciendo anotaciones [en el diario en el mismo diario] en el mismo diario y, cuando quiero escribir una carta como muy emocional, ah:, no se por ejemplo a mis padres, mi madre o: alguna pareja [mju] lo hago siempre a mano $[\mathrm{A} 2 / \mathrm{RO} / 2 / 17]$

Recapitulando, podemos decir que están conscientes que las TIC les ayudan a mantenerse en comunicación constante con otros y les facilitan ciertas prácticas, pero afirman que la tecnología no sustituye la cercanía e interacción que logran frente a frente, y tampoco están dispuestos a renunciar a las prácticas en papel.

Hernández̧, Amaviz̧ca y González, doi: https://doi.org/10.36799/el.v2i1.53 Volumen 2, número 1, Año 2017, ISSN: $2448-5942$ 


\section{El caso de Gabriel y El viaje de Scorchy}

Gabriel mostró tener una actividad variada de prácticas interesantes y rica en producción escrita; gracias a la apertura y confianza que mostró para este trabajo fue que obtuvimos gran cantidad de información.

A lo largo de los años Gabriel ha estado envuelto en prácticas literarias, pero se considera un escritor indisciplinado. Entre el bachillerato y la universidad sintió la necesidad de compartir los cuentos y poemas que había escrito, pero le resultaba complicado hacerlo, primero porque se sentía vulnerable al saber que otros lo leerían, y luego porque no lograba resolver cómo divulgarlos. Así que creó un blog. Le gustaba escribirlos primero a mano y luego postearlos, confiesa que le costó trabajo abandonar esta costumbre:

a veces no tenía la privacidad que quería, la privacidad que me daba un cuaderno y un lápiz, de poder escribir en el balcón, en el parque, en un café, donde se me ocurra ¿no? [mju] eh: y además que la computadora de mi casa pues era: como la de un café Internet, todo mundo podía entrar, mi hermana o, sobre todo mi hermana y mi papá [mju] y este ento...- y además tampoco estaba en un lugar muy o sea, alguien te veía que estaba escribiendo ¿no? entonces yo sentía que perdía privacidad [al escribir en la] al escribir ahí $[\mathrm{A} 2 / \mathrm{GA} / 1 / 7]$

Eventualmente terminó escribiendo directo en el blog. Él mismo dice que parecía un escritor viejo, de esos que se niegan a escribir en la computadora. Alrededor de los seis meses este blog quedó abandonado.

A lo largo de los años ha escrito cuentos, crónicas y ensayos, ha recibido buenas críticas e incluso ganó un premio por este último género. Colabora además en una revista de periodismo narrativo, Gatopardo, que toca temas de interés latinoamericano y también escribe en el blog de Nuestra Aparente Rendición (NAR), que está conformado por un grupo de profesionistas que trabajan por el conocimiento, la comprensión, el respeto y por la paz en México.

como no ha tenido, nunca he tenido buena crítica en cuento y en cambio sí he tenido crítica en ensayo y en crónica, entonces un poco me he dedicado, me he decantado hacia ese género, hacia el ensayo y hacia la crónica [¿no has tenido buena crítica?] ajá, bueno he tenido buena crítica, pero una crítica muy cercana, crítica de amigos, alguna publicación así universitaria, así que ha pues qué bien ¿no? pero, una crítica más extensa 
[ah] o más especializada [ajá] o sea tampoco lo he buscado, pero tampoco: [mju] pero donde si...- siempre he tenido es en el género de crónica o en el género de ensayo [o sea ¿te han publicado cosas? ¿has ganado premios o algo así?] un premio de ensayo en la Pompeu [ah:] un ensayo en la Pompeu, y: y bueno lo que escribo ahora [mju] tiene muy buena, muy buena crítica [m:] la columna que tengo en la Gatopardo [A2/GA/3/24]

Otro de los espacios interesantes que tiene Gabriel para desarrollar su creatividad como escritor es el blog El viaje de Scorchy:

Scorchy es un: gracioso puerco espín de peluche, que: un día encontré en mi: en mi maleta, y: ro...- robándome la idea de Amélie del, del duende viajero, pues lo saqué a, a los viajes que hago aquí en el, en el viejo continente y le empecé a sacar fotos y: y como lo mío no son las fotos sino la escritura [risas] pues dije no pus algo vamos a hacer, algo le doy una identidad a, a Scorchy como mi alter ego, eh: y a través de sus ojos narro eh: mi cotidianidad en Barcelona, los viajes sobre todo [A2/GA/1/7]

El blog se convirtió en un espacio importante en donde podía expresar también cuestiones académicas y a pesar de ser un espacio virtual, donde la escritura es bastante relajada, Gabriel decidió escribir de manera convencional porque, dice, que así fue como aprendió a hacerlo. Es cuidadoso en el proceso de redacción: lee, corrige lo que no le gusta, revisa la ortografía, vuelve a leer y hasta que no está satisfecho con el producto lo publica.

a mí me enseñaron a escribir de una manera determinada, mi papá me pegó en la Preparatoria ahí: lo que tienes que ponerle y todo y, y durante un tiempo siendo joven pues e: con los cuentos sobre todo intentaba transgredir esas, esas, esas normas, tú estás ahí, 'escribe así o como Borges o como yo y sí, entonces no voy a usar puntos ni comas' o cosas así, pero ya después, este, pues lo importante es que, vas aprendiendo que lo importante es que te entiendan, tú quieres transmitir algo y quieres que ese algo llegue a, al receptor que, que tú quieres y: [hay que escribir correctamente para que la gente te entienda:] claro, claro hay que escribir por lo menos de manera sencilla, convencional $[\mathrm{A} 2 / \mathrm{GA} / 3 / 30]$

En la Imagen 1, podemos ver cómo se presenta Scorchy en el blog. 


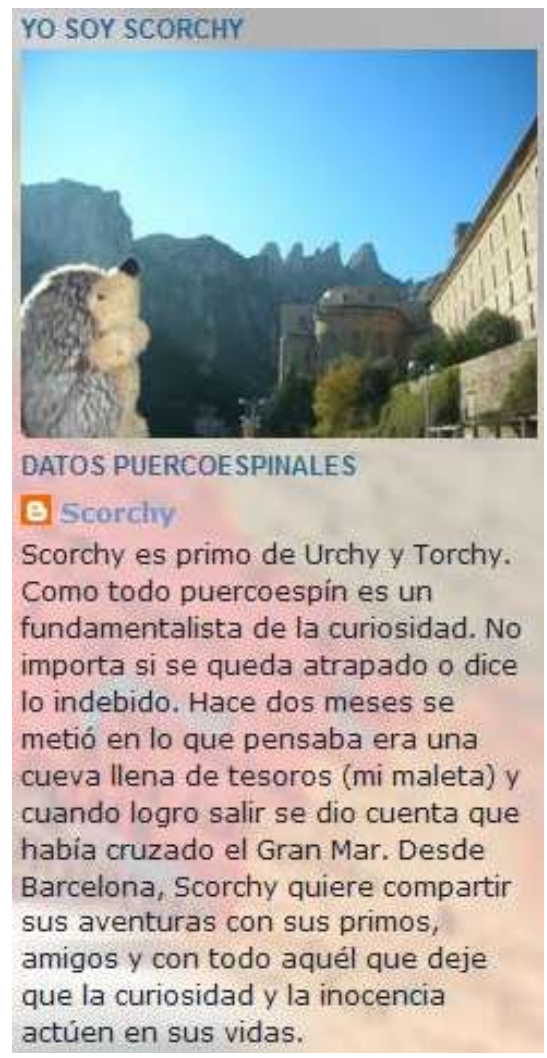

Imagen 1. Presentación de Scorchy

La periodicidad de las publicaciones depende de lo que tenga que contar, de su ánimo al escribir, del tiempo que dispone para dedicarle al texto. Tiene en total 64 textos publicados a lo largo de 45 meses. El total de comentarios, imágenes de los tres años y siete meses que escribió en el blog se muestran en la Tabla 1. También incluimos los textos en español e inglés que publicó.

Tabla 1. Total de publicaciones

\begin{tabular}{|c|c|c|c|c|c|}
\hline Año & Textos & Comentarios & Imágenes & Texto en español & Texto en inglés \\
\hline 1 & 23 & 33 & 38 & 23 & 0 \\
\hline
\end{tabular}

Hernández̧, Amaviz̧ca y González, doi: https://doi.org/10.36799/el.v2i1.53 Volumen 2, número 1, Año 2017, ISSN: $2448-5942$ 


\begin{tabular}{|c|c|c|c|c|c|}
\hline 2 & 22 & 35 & 47 & 22 & 1 \\
\hline 3 & 8 & 13 & 25 & 7 & 1 \\
\hline 4 & 11 & 4 & 36 & 10 & 1 \\
\hline TOTAL $^{5}$ & $\mathbf{6 4}$ & $\mathbf{8 5}$ & $\mathbf{1 4 6}$ & $\mathbf{6 2}$ & $\mathbf{3}$ \\
\hline
\end{tabular}

La hora de publicación varía, puede publicar por la madrugada, durante la tarde o por la noche; a pesar de que los textos están en español el título puede estar escrito en otra lengua (inglés, catalán, árabe, euskera, alemán, checo, francés, polaco). Interpretamos que la variación de lenguas tiene que ver con los lugares a donde viajaba (Lisboa, Roma, París, Bilbao, San Sebastián, Viena, Eslovaquia, Nueva York, Boston, Los Ángeles, Marruecos, Bosnia). Como muchos de sus amigos que visitaba en el extranjero no hablaban español decidía escribir el texto en inglés (para que ellos pudieran leerlo), pero el título de la publicación lo escribía en la lengua en que hablaban sus amigos.

Recibió un total de 85 comentarios de los cuales sólo respondió a uno, la razón de esto, nos dice, es porque considera que el blog es un espacio para leer y no para comentar. Si él hubiera querido tener otro tipo de interacción con los lectores habría escrito sobre otra cosa y en un formato distinto.

Para Gabriel contar estas historias fue una manera de hacer catarsis, una oportunidad de contar desde otro punto de vista -el de Scorchy- lo que pasaba y vivía en sus viajes. El hecho de que las publicaciones disminuyeran con el tiempo tuvo que ver con una saturación de actividades académicas.

El viaje de Scorchy fue un proyecto en el cual Gabriel invirtió mucho tiempo y dedicación. Actualmente el blog está abandonado, piensa retomarlo en algún momento pero considera que debe cambiar el formato ya que le representaba una exigencia en cuanto al proceso y tiempo de redacción.

\footnotetext{
${ }^{5}$ Queremos señalar que el último texto que escribió en el segundo año es bilingüe español-inglés, por ello no coincidirá la cantidad de textos (64), con los textos en español e inglés (que nos dará una suma de 65).
} 
Podemos decir que Gabriel tiene una actividad multimodal variada, además de la gran cantidad de textos que tiene comparte y utiliza muchas fotografías (en su blog y redes sociales), a través de ellas documenta su actividad diaria. Integra estas herramientas dentro de un eje central que es la escritura. Es interesante cómo relaciona cada idioma con una audiencia, una situación y temas específicos, lo cual demuestra mucha conciencia sobre los diferentes perfiles y grupos que se hallan en la red, todos mezclados detrás de la pantalla.

Ve en la tecnología la posibilidad de interactuar con sus amigos, de estar en contacto con su familia, de relacionarse profesionalmente, de compartir parte de su vida a través de la narración, de distribuir conocimiento, de divertirse. Las TIC le facilitan muchas cosas y le hacen más cómodo su quehacer digital.

\section{DISCUSIÓN}

Consideramos que uno de nuestros principales aportes a los NEL es precisamente el estudio a detalle de las prácticas letradas de una población que hasta el momento no había sido estudiada. La mayoría de las investigaciones se centran en los jóvenes millennials, en lo que pueden o no hacer con las TIC, en el uso que le dan a las redes sociales virtuales, en sus características como usuarios ante un mundo virtual en donde lo importante es la rapidez de la publicación de un mensaje, en cuántos seguidores se tiene, en cuántos likes alcanza, etc., y no en la profundidad del contenido a comunicar.

Estudiamos a un grupo de informantes que pertenecen a un porcentaje pequeño de la población mexicana que ha tenido acceso a la educación superior, lo que posiblemente los ha llevado a tener un nivel cultural elevado. Aunado a esto, han tenido la posibilidad de estudiar en el extranjero, enfrentándolos así a situaciones y prácticas diferentes que el resto de estudiantes de posgrado radicados en México no ha podido experimentar. Estas características y situaciones vividas los han puesto en una posición privilegiada en relación con el uso y contacto con la tecnología.

Es probable que el tipo de educación recibida tanto en el seno familiar como en la escuela, en donde la cultura escrita tenía una alta valía -según sus propios testimonios- los haya llevado a tener prácticas letradas similares en el espacio virtual. Los textos, mensajes o 
comentarios que postean deben estar bien escritos, deben comunicar algo, dicho por ellos mismos "no publican cualquier cosa", de ahí que le dediquen tiempo a construirlos y a redactarlos con cuidado, e incluso están dispuestos a recibir comentarios y críticas para mejorarlos. Han sido capaces de establecer un vínculo con sus lectores, existe cierta cooperación entre el escritor y el lector que se ve reflejada en sus prácticas como blogueros ya que, aprovechando las ventajas de la tecnología, borran, corrigen y suben sus textos fácilmente.

Hacen una selección cuidadosa de los documentos que consultan en Internet, conocen las fuentes confiables (revistas, bases de datos, laboratorios, universidades), dominan a sus autores, son escrupulosos con lo que leen y en ocasiones llegan a comparar la versión impresa de un documento con la digital para estar seguros de que la información es la misma, confían en sus contactos - en sus profesores o colegas- cuando postean cierta información y para ellos es suficiente para leerla o compartirla.

A lo largo de las entrevistas y del tiempo que convivimos con ellos tratamos de conocer y situarnos en el momento por el que atravesaban, es decir, no sólo tomamos en cuenta que eran estudiantes de posgrado en el extranjero -y así conocer sus prácticas académicas-, si no de manera personal conocimos sus experiencias en la cotidianidad de la vida -y nos familiarizamos con sus prácticas vernáculas-. Nos compartieron el choque cultural por el cual atravesaron, su situación económica que como becarios era precaria y convivimos con sus propias familias, esta última condición le imprimía otro tipo de situación y características a su estancia como estudiantes. Todo esto de alguna manera impactaba en su forma de relacionarse con las TIC y de usarlas para propósitos muy específicos, aunque no lo pareciera.

Tal como Gallego \& Hollingsworth (2000) lo sugieren, sus múltiples literacidades no eran estáticas, en el caso de Gabriel, por ejemplo, sus prácticas vernáculas se traslapaban con las dominantes; sus temas de interés académicos (seguridad pública, terrorismo, políticas de vigilancia, libertad de prensa, estudios de paz, migración) lo llevaron a viajar por lugares históricos, a ver películas relacionadas con estos temas en sus ratos de ocio, a conocer gente involucrada en activismo, a escribir y documentar relatos. Estas actividades podrían verse también como académicas, sin embargo él mismo declaró no saber dónde se encontraba el límite entre lo profesional y lo personal, entre lo académico y el entretenimiento.

Hernández̧, Amaviz̧ca y González, doi: https://doi.org/10.36799/el.v2i1.53 Volumen 2, número 1, Año 2017, ISSN: $2448-5942$ 
Posiblemente al ser una generación de transición entre la digitalización de los textos y los materiales impresos, la escritura manual continúa siendo relevante para ellos. Descubrimos su gusto por la escritura y el empleo de los blogs para conservar y compartir aquello que escriben; a través de los diarios personales o las cartas, son capaces de expresar emociones y sentimientos que en la pantalla $-\mathrm{O}$ incluso en persona- no pueden hacerlo. Y aunque algunos prefieren seguir manteniendo la tradición de escribir en papel, otros han migrado sus prácticas letradas en formatos impresos a los espacios digitales.

Finalmente queremos señalar que uno de los hallazgos interesantes fue haber presenciado el momento en que se enfrentaron a situaciones nuevas con respecto a las TIC, que permitieron un cambio en su forma de pensar, actuar y concebir a la tecnología ${ }^{6}$, así como los propósitos específicos que le dan a las redes sociales. En varias ocasiones se preguntaron qué de interesante podrían ellos compartir con nosotros con respecto al tema de sus prácticas letradas digitales, les parecía extraño las cosas que les preguntábamos, no veían ninguna relevancia en ello, sin embargo después nos expresaron que en su vida diaria nos recordaban cuando algo interesante les acontecía con respecto al uso de las TIC. Al despedirnos manifestaron ser más conscientes de las cosas que hacían después de haber sido entrevistados.

\section{CONCLUSIONES}

No nos cabe la menor duda de la importancia y del impacto que han tenido las TIC en la vida de estos informantes en general, y en sus prácticas letradas, en particular. Pese a ser informantes de edades parecidas, del mismo país, con una misma formación general básica y ganadores de becas competitivas, cada uno presenta prácticas muy variadas, incluso una misma red social digital como Facebook o Twitter, puede usarse de maneras muy diversas, según los intereses y necesidades de cada informante. Esto sugiere que cada sujeto se apropia de manera muy personal de la tecnología, probablemente esto sea lo que les da tanto éxito a las TIC en sus vidas.

\footnotetext{
${ }^{6}$ Estos hallazgos no fueron objetivo de este artículo pero para conocer sobre estor resultados el lector puede consultar Hernández, D., 2016.

Hernández, Amavižca y González doi: https://doi.org/10.36799/el.v2i1.53 Volumen 2, número 1, Año 2017, ISSN: $2448-5942$
} 
Consideramos que para ellos el espacio virtual es solo una plataforma más en donde pueden realizar sus prácticas de lectura y escritura, así que no tiene por qué ser diferente; reconocen las ventajas de la digitalización, de la rapidez, del costo y de la capacidad almacenamiento que las TIC les ofrecen. Y probablemente las generaciones que tuvimos que aprender a usar esta tecnología veamos las cosas de manera similar.

Son cuidadosos en su forma de escribir, en la selección de sus contactos, en la información que comparten, en su vida pública-digital en general, ya que está de por medio su prestigio como profesionales.

Documentar estas experiencias, sorpresas, miedos de un grupo que conoció y aprendió a usar las TIC en su propio beneficio para potenciar sus prácticas letradas nos parece ya un aporte importante a los NEL. La producción de textos generados por estos informantes fue estupenda y la experiencia de haberse atrevido a hacer públicos sus escritos ha sido gratificante, para los que se atrevieron a ello. El blog de Scorchy es un ejemplo claro de esto.

\section{REFERENCIAS}

Barton, David. y Mary, Hamilton. “Literacy practices”. En Barton, David; Mary, Hamilton y Roz, Ivanic. (Eds.). Situated literacies. Reading and Writing in Context. Londres: Routledge, 1998.

Barton, David. y Mary, Hamilton. "La literacidad entendida como práctica social”. En Zavala, Virginia; Merceder Niño-Murcia y Patricia, Ames. (Eds.). Escritura y sociedad. Nuevas perspectivas teóricas y etnográficas. Perú: Red para el desarrollo de las ciencias sociales en el Perú, 2004.

Brown, John. "Growing up: Digital: How the web changes work, education, and the ways people learn”. USDLA Journal, 16. 2 (2000): s/p. 15 de septiembre del 2016. http://www.usdla.org/html/journal/FEB02_Issue/article01.html 
Camitta, Miriam. "Vernacular writing: varieties of literacy among Philadelphia High School Students”. En Street, Brian (Ed). Cross-cultural approaches to literacy. New York: Cambridge University Press, 1993.

Cassany, Daniel y Denise, Hernández. “¿Internet: 1; Escuela: 0?, CPU-e”. Revista de Investigación Educativa, 14 (2012): s/p. https://www.uv.mx/cpue/num14/opinion/completos/cassany_hernandez_internet_1 _escuela_0.pdf

Gallego, Margaret. \& Hollinsworth, Sandra. (Eds.). The idea of multiple literacies. En Gallego, Margaret. \& Hollinsworth, Sandra. What counts as literacy. Challenging the school standard (123), New York: Teachers College, 2000.

Gee, John. Social linguistics and literacies. New York: The Falmer Press, 1990.

Gee, John. 'The New Literacy Studies. From 'socially situated' to the work of the social”. En Barton, David; Mary, Hamilton y Roz, Ivanic. (Eds.). Situated literacies. Reading and Writing in Context. Nova York: Routledge, 2000.

Heath, Shirley. Ways with words: Language, life and work in communities and classrooms. Cambridge: Cambridge University Press, 1983.

Hernández, Denise. "Los aventurados en el espacio digital: desde la máquina de escribir al correo electrónico". Ensayos pedagógicos, Edición Especial (2016): pp.113-129.

Hernández, Denise; Alberto, Ramírez-Martinell, y Daniel, Cassany. "Categorizando a los usuarios de sistemas digitales". [Versión electrónica] Pixel-Bit. Revista de Medios y Educación, 44 (2014): pp.113-126.

Kalman, Judith. "El acceso a la cultura escrita: la participación social y la apropiación de conocimientos en eventos cotidianos de lectura y escritura". Revista Mexicana de Investigación Educativa, 8.17 (2003): 37-66.

Lankshear, Colin; Paul, Gee; Michele, Knobel y Chris, Searle. Changing Literacies. Great Britain: Open University Press, 1997.

Hernández̧, Amaviz̧ca y González, doi: https://doi.org/10.36799/el.v2i1.53 Volumen 2, número 1, Año 2017, ISSN: $2448-5942$ 
Scribner, Sylvia \& Cole, Michael. The Psychology of Literacy. Cambridge: Harvard University Press, 1981.

Street, Brian. Cross cultural approaches to literacy. Cambridge: Cambridge University Press, 1993.

Street, Brian. Literacy in theory and practice. Cambridge: Cambridge University Press, 1984.

Street, Brian. Social literacies: critical approaches to literacy development, ethnography and education. New York: Longman: 1995. 